\title{
Duloxetine Enteric-coated Tablets Versus Paroxetine in the Treatment of Major Depressive Disorder: A Double-blind, Double-dummy, Randomized Controlled Clinical Trial
}

Jicai Wang ${ }^{1 *}$, Hongyan Jiang ${ }^{1}$, Eugene Chao ${ }^{3}$, Yanjiao Wabg ${ }^{1}$, Wenqing Liu ${ }^{1}$, Xiufeng $\mathrm{Xu}^{1}$, Wenyu $\mathrm{Li}^{1}$, Hong Ouyang ${ }^{1}$, Xiaogang $\mathrm{Chen}^{2}$

${ }^{1}$ Department of Psychiatry, the First Affiliated Hospital of Kunming Medical University, Kunming, Yunnan 650032, China; ${ }^{2}$ Institute of Mental Health, The Second Xiangya Hospital of Central South University, Changsha, Hunan Province, China; ${ }^{3}$ Baylor College of Medicine, Houston, Texas, USA.

*Correspondence: Jicai Wang, Department of Psychiatry, the First Affiliated Hospital of Kunming Medical University, Kunming, Yunnan 650032, China. Email: htjc2002@sina.com

JOURNAL OF PSYCHIATRY AND BRAIN SCIENCE

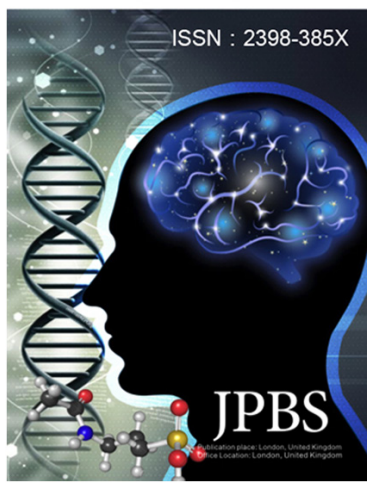

\section{fOPEN ACCESS}

DOI: 10.20900/jpbs.20160006

Received: March 9, 2016

Accepted: May 12, 2016

Published: June 25, 2016

website: http://jpbs.qingres.com

Copyright: $\odot 2016$ Cain et al. This is an open access article distributed under the terms of the Creative Commons Attribution License,which permits unrestricted use, distribution, and reproduction in any medium, provided the original author and source are credited.

Data Availability Statement: All relevant data are within the paper and its Supporting Information files.

Funding: The authors received no specific funding for this work.

Competing Interests: The authors have declared that no competing interests exist.

\section{ABSTRACT}

Objective: To evaluate the efficacy and safety of duloxetine enteric coated tablets in patients with depressive disorders.

Methods: A double-blind, double-dummy, parallel randomized controlled study was carried out for 51 patients who met the DSM-IV criteria of depression and depressed episode. 25 of the total patients were treated with duloxetine $(40-60 \mathrm{mg} \cdot \mathrm{d}-1)$ and the rest were treated with paroxetine $(20 \mathrm{mg} \cdot \mathrm{d}-1)$ for 8 weeks. Efficacy was then assessed by Hamilton Depression Rating Scale (HAMD), Hamilton Anxiety Scale(HAMA), Montgomery Depression Rating Scale (MADRS), Sheehan Disability Scale (SDS), visual analogue scale (VAS-PI) and Clinical Global Impression (CGI). Safety assessments included physical examinations, laboratory evaluations, and electrocardiographic findings of adverse events. Assessment time point were evaluated at baseline and 1,2,4,6,8 weeks after starting treatment.

Results: After 8 weeks of treatment, the total effective rates of duloxetine group and paroxetine group were $72.0 \%$ and $73.1 \%$, respectively, with no significant difference $(t=0.465, P=0.612)$. The clinical curing rates of duloxetine group and paroxetine group were $20.0 \%$ and $23.1 \%$, respectively, with no significant difference $(\mathrm{t}=0.547$, $\mathrm{P}=0.590)$. The scores of HAMD17, HAMA, MADRS, SDS, VAS-PI and CGI in both groups decreased significantly, with statistical difference between the baseline and other observation time points $(P<0.001)$. The adverse event rates of the duloxetine group and paroxetine group were $36.0 \%$ and $34.6 \%$ respectively, with no significant difference $(P>0.05)$. The main adverse events of two groups were dry mouth, nausea, dizziness, and stomach discomfort.

Conclusion: Duloxetine enteric-coated tablet is an effective antidepressant with less side effects, better safety, and more suitable for the treatment of depression patients.

Key words: Duloxetine enteric-coated tablet; paroxetine; major 
depressive disorder; efficacy; safety; randomized controlled trials; double-blinded method

\section{INTRODUCTION}

Major depressive disorder (MDD) is a highly prevalent condition that is associated with significant levels of disability, morbidity, and mortality; its associated lifetime suicide rate is estimated to be $15 \%$.(1) Antidepressants (ADs) are the first-line treatment for depression. Selective serotonin reuptake inhibitors (SSRIs) is the antidepressant commonly used in clinics, because of their good tolerance, convenient taking, and other characteristics. However, the effective rate and remission rate are not satisfactory.

There are evidences that the 5-serotonin and norepinephrine neurotransmitter systems are related to the pathophysiology of depression. Duloxetine is a new antidepressant for the treatment of MDD. It selectively inhibits the uptake of serotonin (5-HT) and norepinephrine (NE) by neurons from the synaptic gap, increases the synaptic pool of available neurotransmitters, and relieves depressive symptoms. $(2,3)$ In vivo and in vitro studies have shown that duloxetine is an effective and balanced inhibitor of 5-HT and NE uptake, with little effect on other neurotransmitter receptors (such as $\mathrm{M}, \mathrm{a} 1$, a2, dopamine D2, and histamine $\mathrm{H} 1$ and $\mathrm{H} 2$ receptors).(4,5) The efficacy of duloxetine in reducing depressive symptoms has been demonstrated in patients with MDD,(6) comparable to efficacy to selective 5-HT reuptake inhibitors such as fluoxetine, paroxetine, citalopram, and sertraline. $(7,8)$ Duloxetine has also been reported to be effective in the treatment of generalized anxiety disorder,(9) fibromyalgia.(10) Diabetic Peripheral Neuropathic Pain,(11) pathological laughing and crying,(12) and improvement of cognitive function in depression patients.(13) Overall, duloxetine has been well tolerated across all trials. $(7,8,14)$

This study aims to evaluate duloxetine enteric-coated tablet (manufactured by Jiangsu Nhwa Pharmaceutical Co., Ltd. in China) treatment efficacy and safety of Chinese patients with depression.

\section{METHODS}

\section{Objectives}

The patients were enrolled in the First Affiliated Hospital of Kunming Medical University. All the patients met the inclusion criteria for the study: current MDD as diagnosed by the Statistical Manual of Mental Disorders IV (DSM-IV) criteria; aged 18-65 years; 17-item Hamilton Depression rating scale (HAMD-17) score of 20 or above with the depressed mood item scored 2 or more (range 0-4); the severity item of the Clinical Global Impression scale (CGI-S) scored 4 or above (range 1-7); and signed inform consent of the patients themselves or their legal guardians.

Patients who met any of the following exclusion criteria were not enrolled in the study: the presence of other mental disorders with depression in the diagnosis of I DSM-IV axis; reports of suicidal ideation or prior suicide attempt; any possible interference on patients in the study or increase on the risk of destabilizing the heart, lung, liver, kidney, eye, cardiovascular, nervous system, endocrine system, blood system other diseases; history of epilepsy (except for febrile convulsion in children); increased intraocular pressure or angle-closure glaucoma history; psychoactive substance abuse or dependence in the prior year; rapid cycling episodes of depression; depressive episodes secondary to other psychiatric or somatic disorders; allergies to duloxetine or paroxetine; pregnant, breast-feeding, or of childbearing age and not taking effective contraceptive measures; abnormal ECG or laboratory results that researchers believe may affect the evaluation of efficacy and safety; liver enzymes elevated more than twofold the upper limit of normal; history of serious drug allergy; treatment of monoamine oxidase inhibitors four weeks before randomization; participation of a clinical trial within the past 30 days; discontinued treatment with psychotropic drugs (except hypnotics) less than five half-lives before randomization; previous non-responsiveness to therapy with duloxetine hydrochloride or paroxetine hydrochloride; receiving of electroconvulsive therapy (ECT) within the past six months; the decrease of more than 25\% baseline HAMD17 total score relative to screening; inability to be compliant with the therapy; or any other factors leading investigators to believe the individual was inappropriate for recruitment.

During the treatment, the patients who met any of the following criteria was withdrawn or dropped out the trial: adverse events or abnormal laboratory values determined by the researchers; patient withdrawal from the trial; violation of the study protocol (subjects did not meet the inclusion criteria; failure to comply with program); subjects in the trial process of pregnancy; consent withdrawal, or lack of follow-up.

According to the above conditions, 54 patients were enrolled in this study; 3 patients fell off, leving 51 
patients (duloxetine enteric coated tablets group 25 cases, paroxetine group 26 cases) for actual completion.

Duloxetine Enteric Coated Tablets Group: 25 cases, 12 cases of male, 13 female patients; aged $19-57$ years, mean age $(37.32 \pm 9.86)$ years; mean current course $(3.38-6.48)$ months; mean total illness course $(20.90 \pm 18.75)$ months; mean years of education $(10.76 \pm 3.35)$ years; at baseline, mean total score $(22.08 \pm 1.80)$, mean MADRS total score $(36.93 \pm 3.28)$, mean HAMA total score $(19.00 \pm 2.35)$; clinical global impression rating table - the severity of the disease (CGI - s) assessment: 22 cases of moderate, 3 cases of markedly.

Paroxetine Group: 26 cases, 9 cases of male, 13 female patients; aged 22-60years, mean age $(40.38 \pm 11.15)$ years; mean current course $(2.15-2.33)$ months; mean total illness course $(28.87 \pm 27.58)$ months; mean years of education $(9.15 \pm 2.94)$ years; at baseline, mean total score $(21.85 \pm 1.60)$, mean MADRS total score (36.03 \pm 2.39 ), mean HAMA total score (19.74 \pm 2.14 ); clinical global impression rating table - the severity of the disease (CGI - s) assessment: 24 cases of moderate, 2 cases of markedly.

There were was significant difference in demographic data (age, sex, height, weight and others) and psychotic features (incidence frequency, the course of disease; history of physical diseases, the physical examination and vital signs) $(P>0.05)$ between two groups.

\section{Study Design}

An eight-week randomized, double-blind, double-dummy, parallel-group, positive drug (paroxetine) clinical trial was carried out, where 51 patients were randomly enrolled into duloxetine group or paroxetine group. Before treatment, there was placebo rinsing of 0-7 days. In the duloxetine group, patients were treated with duloxetine $(40 \mathrm{mg} / \mathrm{d}$ ) and paroxetine placebo (1 tablet) each morning during week one, and with duloxetine $(60 \mathrm{mg} / \mathrm{d})$ and paroxetine placebo (1 tablet) from week two to week eight. In the paroxetine group, patients were treated with paroxetine $(20 \mathrm{mg} / \mathrm{d})$ and duloxetine placebo (2 tablets) each morning during week one, and with paroxetine $(20 \mathrm{mg} / \mathrm{d})$ and duloxetine placebo (3 tablets) from week two to week eight. Jiangsu Nhwa Pharmaceutical Co, Ltd. provided the medications used in the study: enteric-coated duloxetine hydrochloride tablets (20mg/tablet; drug lot number 20090401; Jiangsu Nhwa Pharmaceutical Co., Ltd.), and paroxetine hydrochloride tablets (Seroxat; 20 mg/tablet; drug lot number 9040747; Glaxo SmithKline Pharmaceutical Co.,Ltd.).

During the study, drugs were used at conventional doses for the treatment of insomnia (zolpidem, zopiclone, zaleplon) at night. To control physical diseases, the researcher recorded the names, dose of each allowed drug and the duration of treatment in detail. However, other antipsychotics, antidepressants, anxiolytics, mood stabilizers, as well as modified electroconvulsive therapy, and systemic psychotherapy (such as cognitive and behavioral therapy), were not allowed.

\section{Efficacy and Safety Rating}

The HAMD-17, the Hamilton Anxiety scale (HAMA), the Montgomery and Asberg Depression Rating Scale (MADRS), the severity measure of the Clinical Global Impression scale (CGI-S), the Visual Analog Scale of Pain Intensity (VAS-PI), and the SheehanDisability Scale (SDS) were assessed at baseline and at the end of the 1st, 2nd, 4th, 6th, and 8th week of treatment. The occurrence of any adverse events was also recorded at each of the these clinical visits. The total HAMD-17 score after eight weeks of treatment and the difference between the HAMD-17 score at baseline and after eight weeks of treatment were used as the primary measures of therapeutic efficacy. Clinical remission was defined as a HAMD-17 score of $\leq 7$ by the end of the trial. Effectiveness was defined as a decrease of at least $50 \%$ of baseline HAMD-17 score at the end of the trial. The total scores, differences in scores, effectiveness, and clinical remission rates were compared between the two groups.

The following laboratory examinations were carried out at baseline, at the end of the 8-week trial, and at any time if necessary: routine blood tests; routine urine tests ;blood biochemistry to determine liver function, kidney function, and fasting blood glucose; a urine pregnancy test (women only); and a 12-lead electrocardiographic examination; blood pressure; body weight.

\section{Statistical Analysis}

All data were done by professionals using SAS9.1 statistical software for chi square test, Fisher exact test, $\mathrm{t}$-test, Wilcoxon rank sum test, analysis of variance, $\mathrm{CMH}$ analysis, etc.. All the significant tests were twosided test, $\alpha=0.05$.

The protocol for this study was approved by the Ethics Committee of the First Affiliated Hospital of Kunming Medical University. 


\section{RESULTS}

\section{Efficacy Analysis}

As shown in Table 1, the HAMD-17 scores decreased significantly from baseline over the course of therapy in both groups. There were no significant differences in the magnitude of the change in HAMD-17 from baseline between the two groups at any point over the 8-week treatment trial.

At the end of the treatment, the duloxetine group and paroxetine group HAMD score reduction rate was $53.10 \%, 52.02 \%$, effective rate $72.0 \%, 73.1 \%$, and remission rate $20.0 \%, 23.1 \%$,respectively, and the difference between the two groups was not significant $(\mathrm{t}=0.427, \mathrm{P}=0.674 ; \mathrm{t}=0.465, \mathrm{P}=0.612 ; \mathrm{t}=0.547, \mathrm{P}=$ 0.590).

Table 1 HAMD-17 Scores at Different Time Points during the Trial in Two Groups of patients with Major Depressive Disorder

\begin{tabular}{ccccccc}
\hline & baseline & \multicolumn{5}{c}{ after treatment time point } \\
\cline { 3 - 7 } & & $1 \mathrm{~W}$ & $2 \mathrm{~W}$ & $4 \mathrm{~W}$ & $6 \mathrm{~W}$ & $8 \mathrm{~W}$ \\
\hline $\begin{array}{c}\text { duloxetine } \\
\text { group }(\mathrm{n}=25) \\
\text { paroxetine } \\
\text { group }(\mathrm{n}=26)\end{array}$ & $22.08 \pm 1.80$ & $20.37 \pm 1.55$ & $17.52 \pm 1.83$ & $14.28 \pm 2.49$ & $11.80 \pm 2.75$ & $10.60 \pm 2.94$ \\
$\mathrm{t}$ & $21.85 \pm 1.60$ & $20.74 \pm 1.61$ & $18.08 \pm 2.08$ & $15.01 \pm 2.71$ & $11.85 \pm 3.32$ & $10.23 \pm 3.61$ \\
$\mathrm{P}$ & 0.326 & 0.862 & 1.040 & 0.986 & 0.054 & 0.401 \\
\hline
\end{tabular}

During the 8 weeks of treatment, the scores of anxiety / somatic, cognitive impairment, block and sleep disturbance of HAMD-17 were similar between the groups, and there was no significant difference between the two groups $(P>0.05)$. In addition to no changes in body weight factor, other factors were significantly lower than baseline $(P<0.001)$. See Table 2,3.

Table 2 HAMD Factor Score Changes between the Group Comparisons (baseline - 8 weekend)

\begin{tabular}{lcccc}
\hline & duloxetine group $(\mathrm{n}=25)$ & paroxetine group $(\mathrm{n}=26)$ & $\mathrm{t}$ & $\mathrm{P}$ \\
\hline anxiety / somatic & $3.64 \pm 1.19$ & $3.07 \pm 1.60$ & 1.433 & 0.159 \\
cognitive impairment & $2.20 \pm 0.82$ & $2.19 \pm 0.90$ & 0.032 & 0.975 \\
block & $3.24 \pm 1.33$ & $4.04 \pm 1.78$ & 1.820 & 0.075 \\
sleep disturbance & $2.40 \pm 0.82$ & $2.27 \pm 0.87$ & 0.552 & 0.583 \\
\hline
\end{tabular}

Table 3 Within the Group of HAMD Factor Scores before and after Treatment

baseline $\quad 8$ week $\quad t(P)$




\begin{tabular}{lllll}
\hline & anxiety / somatic & $8.16 \pm 1.89$ & $4.52 \pm 1.04$ & $15.35(0.00)$ \\
duloxetine & cognitive impairment & $2.36 \pm 0.86$ & $0.16 \pm 0.37$ & $13.47(0.00)$ \\
group $(\mathrm{n}=25)$ & block & $7.32 \pm 1.94$ & $4.08 \pm 1.47$ & $12.17(0.00)$ \\
& sleep disturbance & $4.24 \pm 0.66$ & $1.84 \pm 0.62$ & $14.70(0.00)$ \\
\hline & anxiety / somatic & $7.77 \pm 1.99$ & $4.69 \pm 1.34$ & $9.82(0.00)$ \\
paroxetine & cognitive impairment & $2.35 \pm 0.79$ & $0.15 \pm 0.46$ & $12.49(0.00)$ \\
group $(\mathrm{n}=26)$ & block & $7.54 \pm 1.90$ & $3.50 \pm 1.68$ & $11.59(0.00)$ \\
& sleep disturbance & $4.15 \pm 0.74$ & $1.88 \pm 0.65$ & $13.23(0.00)$ \\
\hline
\end{tabular}

The HAMA scores decreased significantly from baseline over the course of therapy in both groups. There were no significant differences in the magnitude of the change in HAMa from baseline between the two groups at any point over the 8-week treatment trial, see Table 4.

At the treatment of 8 weeks, the scores of psychic anxiety and somatic anxiety of HAMA in the two groups were similar to baseline reduction in the groups, between the two groups no significant difference $(P>0.05)$, and all were significant compared to baseline reduction $(P<0.001)$, see Tables 5,6 .

Table 4 HAMA Scores at Different Time points during the Trial in Two Groups of Patients with Major Depressive Disorder

\begin{tabular}{|c|c|c|c|c|c|c|}
\hline & \multirow[t]{2}{*}{ baseline } & \multicolumn{5}{|c|}{ after treatment time point } \\
\hline & & $1 \mathrm{~W}$ & $2 W$ & $4 W$ & $6 W$ & $8 W$ \\
\hline $\begin{array}{c}\text { duloxetine } \\
\text { group }(n=25)\end{array}$ & $19.00 \pm 2.35$ & $17.67 \pm 1.82$ & $14.85 \pm 2.05$ & $12.72 \pm 2.21$ & $11.16 \pm 2.48$ & $10.00 \pm 3.01$ \\
\hline $\begin{array}{c}\text { paroxetine } \\
\text { group }(n=26)\end{array}$ & $19.74 \pm 2.14$ & $18.44 \pm 12.01$ & $15.96 \pm 2.54$ & $13.76 \pm 1.99$ & $11.19 \pm 2.71$ & $9.96 \pm 2.84$ \\
\hline $\mathrm{t}$ & 1.210 & 1.492 & 1.754 & 1.782 & 0.044 & 0.047 \\
\hline$P$ & 0.232 & 0.142 & 0.085 & 0.081 & 0.965 & 0.963 \\
\hline
\end{tabular}

Table 5 HAMA Factor Score Changes between the Group Comparisons (baseline -8 weekend)

\begin{tabular}{|c|c|c|c|c|}
\hline & duloxetine group $(n=25)$ & paroxetine group $(n=26)$ & $\mathrm{t}$ & $\mathrm{P}$ \\
\hline psychic anxiety & $4.88 \pm 2.64$ & $5.65 \pm 2.28$ & 1.123 & 0.267 \\
\hline Somatic anxiety & $4.48 \pm 1.85$ & $4.42 \pm 2.25$ & 0.098 & 0.922 \\
\hline
\end{tabular}

Table 6 Within the Group of HAMA Factor Scores before and after Treatment

baseline $\quad 8$ week $\quad t(P)$




\begin{tabular}{ccccc}
\hline $\begin{array}{c}\text { duloxetine } \\
\text { group }(\mathrm{n}=25)\end{array}$ & psychic anxiety & $11.48 \pm 1.66$ & $6.60 \pm 2.06$ & $11.16(0.00)$ \\
& Somatic anxiety & $9.76 \pm 1.33$ & $5.28 \pm 1.62$ & $14.80(0.00)$ \\
\hline $\begin{array}{c}\text { paroxetine } \\
\text { group }(\mathrm{n}=26)\end{array}$ & psychic anxiety & $11.00 \pm 1.33$ & $6.34 \pm 170$ & $14.89(0.00)$ \\
& Somatic anxiety & $9.77 \pm 1.10$ & $5.35 \pm 2.22$ & $12.30(0.00)$ \\
\hline
\end{tabular}

The MADRS, VAS-PI, SDS, CGI-S scores decreased significantly from baseline over the course of therapy in both groups. There were no significant differences in the magnitude of the change in MADRS, VAS-PI, SDS, CGI-S from baseline between the two groups at any point over the 8-week treatment trial. See Table 7, 8, 9,10.

Table 7 The MADRS Scores at Different time Points during the Trial in Two Groups of Patients with Major Depressive Disorder

\begin{tabular}{|c|c|c|c|c|c|c|}
\hline & \multirow[t]{2}{*}{ baseline } & \multicolumn{5}{|c|}{ after treatment time point } \\
\hline & & $1 \mathrm{~W}$ & $2 W$ & $4 \mathrm{~W}$ & $6 \mathrm{~W}$ & $8 W$ \\
\hline $\begin{array}{c}\text { duloxetine } \\
\text { group }(n=25)\end{array}$ & $36.93 \pm 3.28$ & $35.56 \pm 2.86$ & $31.78 \pm 3.30$ & $26.96 \pm 4.26$ & $22.56 \pm 5.51$ & $20.40 \pm 6.11$ \\
\hline $\begin{array}{c}\text { paroxetine } \\
\text { group }(n=26)\end{array}$ & $36.03 \pm 2.39$ & $34.85 \pm 2.32$ & $31.88 \pm 2.92$ & $27.54 \pm 4.01$ & $22.50 \pm 5.49$ & $19.46 \pm 6.20$ \\
\hline$t$ & 1.137 & 0.994 & 0.125 & 0.500 & 0.039 & 0.544 \\
\hline$P$ & 0.261 & 0.325 & 0.901 & 0.620 & 0.969 & 0.589 \\
\hline
\end{tabular}

Table 8 Comparison of MADRS Total Score before and after Treatment

\begin{tabular}{lccc}
\hline & baseline & 8 week & $t(P)$ \\
\hline duloxetine group $(n=25)$ & $36.93 \pm 3.28$ & $20.40 \pm 6.11$ & $14.90(0.00)$ \\
paroxetine group $(n=26$ & $36.03 \pm 2.39$ & $19.46 \pm 6.20$ & $13.46(0.00)$ \\
\hline
\end{tabular}

Table 9 The VAS-PI Scale Scores at Different Time Points during the Trial in the Two Group of Patients with Depressive Disorder

\begin{tabular}{llcccc}
\hline & baseline & & \multicolumn{3}{c}{ after treatment time point } \\
\cline { 3 - 6 } & & $2 \mathrm{~W}$ & $4 \mathrm{~W}$ & $6 \mathrm{~W}$ & $8 \mathrm{~W}$ \\
\hline duloxetine group $(\mathrm{n}=25)$ & $27.15 \pm 5.27$ & $20.96 \pm 4.94$ & $15.28 \pm 4.98$ & $9.56 \pm 6.01$ & $7.64 \pm 7.33$
\end{tabular}




$\begin{array}{cccccc}\text { paroxetine group }(\mathrm{n}=26) & 25.78 \pm 5.70 & 21.34 \pm 6.56 & 15.54 \pm 6360 & 9.31 \pm 6.63 & 6.57 \pm 6.49 \\ \mathrm{t} & 0.916 & 0.241 & 0.157 & 0.142 & 0.547 \\ \mathrm{P} & 0.364 & 0.812 & 0.875 & 0.887 & 0.587\end{array}$

Table 10 Sheehan Disability Scale Scores at Different Time Points during the Trial in Two Groups of Patients with Major Depressive Disorder

\begin{tabular}{|c|c|c|c|c|c|}
\hline & \multirow[t]{2}{*}{ baseline } & \multicolumn{4}{|c|}{ after treatment time point } \\
\hline & & $2 W$ & $4 W$ & $6 \mathrm{~W}$ & $8 W$ \\
\hline duloxetine group $(n=25)$ & $23.67 \pm 3.19$ & $19.33 \pm 3.43$ & $16.24 \pm 3.62$ & $13.72 \pm 4.84$ & $11.60 \pm 4.82$ \\
\hline paroxetine group $(n=26$ & $24.15 \pm 3.30$ & $20.42 \pm 3.95$ & $17.34 \pm 3.69$ & $1342 \pm 4.77$ & $10.88 \pm 5.05$ \\
\hline $\mathrm{t}$ & 0.545 & 1.073 & 1.081 & 0.221 & 0.517 \\
\hline $\mathrm{P}$ & 0.588 & 0.290 & 0.285 & 0.826 & 0.607 \\
\hline
\end{tabular}

Table 11 CGI-S Scores at Different Time Points during the Trial in Two Groups of Patients with Major Depressive Disorder

\begin{tabular}{|c|c|c|c|c|c|c|}
\hline & \multirow[t]{2}{*}{ baseline } & \multicolumn{5}{|c|}{ after treatment time point } \\
\hline & & $1 \mathrm{~W}$ & $2 W$ & $4 \mathrm{~W}$ & $6 \mathrm{~W}$ & $8 W$ \\
\hline duloxetine group $(n=25)$ & $4.15 \pm 0.36$ & $3.93 \pm 0.47$ & $3.30 \pm 0.61$ & $3.04 \pm 0.35$ & $2.68 \pm 0.56$ & $2.48 \pm 0.65$ \\
\hline paroxetine group $(n=26$ & $4.07 \pm 0.27$ & $3.85 \pm 0.46$ & $3.19 \pm 0.40$ & $3.03 \pm 0.20$ & $2.58 \pm 0.58$ & $2.35 \pm 0.63$ \\
\hline $\mathrm{t}$ & 0.856 & 0.585 & 0.737 & 0.019 & 0.649 & 0.746 \\
\hline $\mathrm{P}$ & 0.396 & 0.561 & 0.465 & 0.985 & 0.519 & 0.460 \\
\hline
\end{tabular}

\section{Safety Analysis}

During treatment, the incidence rate of adverse events in duloxetine group and paroxetine group were $36.0 \%$ and $34.6 \%$, respectively. There was no statistical difference between the two groups $(P>0.05)$. In addition to dry mouth, the rest of the adverse events rate also showed no significant difference $(P>0.05)$. Common adverse events included dry mouth, nausea, dizziness, stomach discomfort, and blurred vision. These adverse events were mild to moderate, of short duration, and resolved without any specific management, and done to not affect the physical and social function of the patient. No serious adverse events occurred during the whole trial period.

The urine leucocyte were increased in two patients of duloxetine group, one patient of paroxetine group; serum alanine aminotransferase (ALT) and aspartate aminotransferase (AST) were abnormal in one patient of paroxetine group, one patient of paroxetine group suffered from ventricular premature beat. At the end of 
the treatment, the patients were followed up and the examination results turned out normal. There was no significant difference in blood pressure, heart rate, respiratory rate, weight of two treatment groups before and after treatment $(P>0.05)$.

\section{Combined Drug Analysis}

In the course of treatment, main drug combination was zolpidem which duloxetine group 8 (32.0\%), paroxetine group 7 cases $(26.9 \%)$, using reason for bad sleep at night. the two groups with the types of medication, medication, the proportion of patients with medication were no statistical difference $(P>0.05)$.

\section{DISCUSSION}

Duloxetine hydrochloride, a serotonin-norepinephrine reuptake inhibitor (SNRI), was approved by the United States Food and Drug Administration (FDA) for the treatment of MDD in 2004, and supported by four short-term and one maintenance trial studies in adult patients. The affinity between duloxetine and other neurotransmitter receptors (such as $\mathrm{M}$, a1, a2, dopamine D2, and histamine $\mathrm{H} 1$ and $\mathrm{H} 2$ receptors) is very small, so it has less cholinergic and cardiovascular adverse reactions. $(2,3,5,15)$

Clinical studies showed that treatment effect in depression of duloxetine was significantly better than that of placebo, and similar to tricyclic antidepressants (TCA), selective serotonin reuptake inhibitors(SSRI), and selective noradrenalin reuptake inhibitors (SNRI). The efficacy of duloxetine in the treatment of the painful somatic symptoms of depression was better than that of the placebo. In addition, owing to its rapid-action profile, duloxetine is conducive to improve the recovery rate of depression.(16-21)

This study is a randomized, double-blind, double-dummy, parallel-group, positive drug (paroxetine) clinical trial, and aims to evaluate the efficacy, safety and tolerance of duloxetine enteric-coated tablet produced by Jiangsu Nhwa Pharmaceutical Co., Ltd in China for the treatment of major depressive disorders in Chinese patients.

This clinical study showed that duloxetine enteric coated tablets had definite effect on depression. The HAMD score and the score of each factor in the two groups were significantly lower than those at the end of treatment. HAMD-17 score reduction was found to be $11.48 \pm 2.89$ and $11.61 \pm 3.77$ in the duloxetine and paroxetine groups, respectively, with no statistically significant ( $t=0.144, P=0.886$ ) difference; the HAMD score reduction rate of duloxetine enteric coated tablets group and paroxetine group was $53.10 \%$ and $52.02 \%$, respectively, with no statistically significant $(\mathrm{t}=0.427 \mathrm{P}=0.674)$ difference; the total effective rate and remission rate of duloxetine enteric coated tablets group and paroxetine group was $72.0 \%, 73.1 \%, 20.0 \%$ and $23.1 \%$, respectively, with no significant difference $(\mathrm{t}=0.465, \mathrm{P}=0.612 ; \mathrm{t}=0.547, \mathrm{P}=0.590)$.

The secondary clinical measures all showed significant improvement over the 8-week trial, with no significant difference in the magnitude of the change in scores between the two treatment groups. The HAMA score and the score of each factor in the two groups were significantly lower than those at the end of treatment; while the HAMA score reduction was found to be $9.13 \pm 3.76$ and $9.77 \pm 3.23$ in the duloxetine and paroxetine groups, respectively, the difference was not statistically significant $(t=0.905, P=0.370)$; MADRS, CGI, VAS-PI, SDS scale score at the end of treatment was significantly lower than the baseline $(P<0.001)$, indicating that duloxetine enteric coated tablets had significant effect on depression, anxiety, and somatic pain symptoms, as well as improved $\mathrm{h}$ working ability, social and family function and quality of life of the depression of patients, a result consistent with many studies or trial.(13,22-28)

Many studies have shown that duloxetine has obvious effective in relieving the diabetic peripheral neuropathic pain and fibromyalgia pain syndrome, as well as good therapeutic efficiency and safety in the treatment of the elderly, in adolescents with depression, generalized anxiety disorder(GAD), obsessivecompulsive disorder(OCD), pathological laughing and crying(PLC),(12,29-32) and cognitive function of patients with depression.(13,33) It has no effect on sexual function, an improvement on the SSRI drug sexual dysfunction $(34,35)$. Not only can it be used for the acute phase of treatment, but also for long-term maintenance treatment, which reduces the recurrence rate of depression.(36)

In the safety analysis, adverse reaction cases and incidence rate of two groups had no significant difference (duloxetine enteric coated tablets group 36.0\%, paroxetine group 34.6\%), indicating that the adverse reactions in the two groups are equivalent. The common side effects for duloxetine reported in this study are nausea, dry mouth, dizziness, stomach discomfort, blurred vision. However, these side effects were largely mild to moderate in severity and did not require specific therapy or management, which was consistent with the results of many studies.(37-39) In this study, duloxetine had no detrimental effect on routine blood test,kidney and liver function, heart rate, respiratory rate, blood pressure, or body weight. 
In a word, this study showed that duloxetine enteric coated tablets had definite therapeutic effect on depression and anxiety, relieved somatic pain, and improved social function, had less adverse reaction, and thus was a new safe and effective antidepressant.

\section{REFERENCE}

1. Budam, Tsuangmt. The epidemiology of suicide: implications for clinical practice. In: S.I. Blumenthal and D.J. Kupfer, editors, suicide over the life cycle: risk factors, assessments and treatment of suicide patients [M]. WashingtonDC: AmericanPsychiatricPress, 1981.

2. Müller N, Schennach R, Riedel M, Mller HJ. Duloxetine in the treatment of major psychiatric and neuropathic disorders[J]. Expert Rev Neurother,2008,8(4) : 527-536.

3. Knadler MP, Lobo E, Chappell J, Bergstrom R. Duloxetine: clinical pharmacokinetics and drug interactions. Clin Pharmacokinet. 2011,50(5):281-294

4. Westanmo AD, Gayken J, Haight R. Duloxetine: a balanced and selective norepinephrine- and serotoninreuptake inhibitor. Am J Health Syst Pharm. 2005; 62(23): 2481-2490,

5. Bymaster FP, Dreshfield-Ahmad LJ, Threlkeld PG, Shaw JL, Thompson L, Nelson DL, Hemrick-Luecke SK, Wong DT. Comparative affinity of duloxetine and venlafaxine for serotonin and norepinephrine transporters in vitro and in vivo, human serotonin receptor subtypes, and other neuronal receptors. Neuropsychopharmacology, 2001 Dec;25(6):871-880.

6. Ball SG, Desaiah D, Zhang Q, Thase ME, Perahia DG. Efficacy and safety of duloxetine $60 \mathrm{mg}$ once daily in major depressive disorder: a review with expert commentary. Drugs Context, 2013; 2013: 212245.

7. Thase ME, Pritchett YL, Ossanna MJ, Swindle RW, Xu J, Detke MJ. Efficacy of duloxetine and selective serotonin reuptake inhibitors: comparisons as assessed by remission rates in patients with major depressive disorder. J Clin Psychopharmacol. 2007; 27(6): 672-676.

8. Goldstein DJ, Lu Y, Detke MJ, Wiltse C, Mallinckrodt C, Demitrack MA. Duloxetine in the treatment of depression: A double blind placebo controlled comparison with paroxetine. J Clin Psychopharmacol. 2004; 24(4): 389-399.

9. Carter NJ, McCormack PL. Duloxetine: a review of its use in the treatment of generalized anxiety disorder. CNS Drugs. 2009; 23(6): 523-541.

10. Arnold LM, Zhang S, Pangallo BA. Efficacy and safety of duloxetine $30 \mathrm{mg} / \mathrm{d}$ in patients with fibromyalgia: a randomized, double-blind, placebo-controlled study. Clin J Pain. 2012; 28(9): 775-781.

11. Ormseth MJ, Scholz BA, Boomershine CS. Duloxetine in the management of diabetic peripheral neuropathic pain. Patient Prefer Adherence. 2011,5:343-356.

12. Ferentinos $P$, Paparrigopoulos $T$, Rentzos M, Evdokimidis I.Duloxetine for pathological laughing and crying. Int J Neuropsychopharmacol. 2009 Nov;12(10):1429-1430.

13. Framptom JE, Plosker GL. Duloxetine: a review of its use in the treatment of major dep ressive disorder [J]. CNS Drugs, 2007, 21(7) : 581-609.

14. Wilhelm S, Boess FG, Hegerl U, Mergl R, Linden M, Schacht A, Schneider E. Tolerability aspects in duloxetine-treated patients with depression: should one use a lower starting dose in clinical practice? Expert Opin Drug Saf. 2012,11(5):699-711.

15. Hunziker ME, Suehs BT, Bettinger TL, Crismon ML. Duloxetine Hydrochloride: a new dual-acting medication for the treatment of major depressive disorder[J]. ClinTher, 2005, 27(8):1126 -1143.

16. Brannan SK, Mallinckrodt CH, Detke MJ, Watkin JG, Tollefson GD. Onset of action for duloxetine $60 \mathrm{mg}$ once daily: double blind, placebo controlled studies[J]. J Psychiatr Res, 2005, 39(2) : 161-172.

17. Detke MJ, Lu Y, Goldstein DJ, McNamara RK, Demitrack MA. Duloxetine 60 mg once daily dosing versus placebo in the acute treatment of major depression[J]. J Psychiatr Res, 2002,36(6):383- 390.

18. Detke MJ, Lu Y, Goldstein DJ, Hayes JR, Demitrack MA.Duloxetine60mg once-daily formajor depressive disorder: A randomized double-blind placebo-controlled trial[J]. J Clin Psychiatry, 2002, 63(4):308 -315.

19. Dunner DL, D'Souza DN, Kajdasz DK, Detke MJ, Russell JM. Is treatment-associated hypomania rare 
with duloxetine: secondary analysis of controlled trials in non-bipolar depression[J]. J Affect Disord,2005, $87(1): 115-119$.

20. Stewart DE, Wohlreich MM, Mallinckrodt CH, Watkin JG, Kornstein SG. Duloxetine in the treatment of major depressive disorder: comparisons of safety and tolerability in male and female patients[J]. J Affect Disord, 2006, 94(1 -3):183 -189.

21. Greist J, McNamara RK, Mallinckrodt CH, Rayamajhi JN, Raskin J. Incidence and duration of antidepressant-induced nausea: duloxetine compared with paroxetine and fluoxetine [J] .ClinTher,2004, 26(9):1446 -1455.

22. Able SL, Cui Z, Shen W. Duloxetine treatment adherence across mental health and chronic pain conditions. Clinicoecon Outcomes Res. 2014 Feb 11;6:75-81.

23. Hellerstein DJ, Stewart JW, McGrath PJ, Deliyannides DA, Batchelder ST, Black SR, Withers A, O'Shea D, Chen Y. A randomized controlled trial of duloxetine versus placebo in the treatment of nonmajor chronic depression. J Clin Psychiatry. 2012,73(7):984-991.

24.Gueorguieva R, Mallinckrodt C, Krystal JH. Trajectories of depression severity in clinical trials of duloxetine: insights into antidepressant and placebo responses. Arch Gen Psychiat ry.2011,68(12):1227-1237.

25. Thaler KJ, Morgan LC, Van Noord M, Gaynes BN, Hansen RA, Lux LJ, Krebs EE, Lohr KN, Gartlehner G.. Comparative effectiveness of second-generation antidepressants for accompanying anxiety, insomnia, and pain in depressed patients: a systematic review. Depress Anxiety. 2012,29(6):495-505.

26. Gaynor PJ, Gopal M, Zheng W, Martinez JM, Robinson MJ, Marangell LB.. A randomized placebocontrolled trial of duloxetine in patients with major depressive disorder and associated painful physical symptoms. Curr Med Res Opin. 2011,27(10):1849-1858.

27. Mancini M, Sheehan DV, Demyttenaere K, Amore M, Deberdt W, Quail D, Sagman D.Evaluation of the effect of duloxetine treatment on functioning as measured by the Sheehan disability scale: pooled analysis of data from six randomized, double-blind, placebo-controlled clinical studies. Int Clin Psychopharmacol. 2012 Nov;27(6):298-309.

28. Happich M, Schneider E, Wilhelm S, Zimmermann T, Schacht A. Depression treatment with duloxetine and reduction of inability to work. Depress Res Treat. 2012,:264854

29. Wu WY, Wang G, Ball SG, Desaiah D, Ang QQ. Duloxetine versus placebo in the treatment of patients with generalized anxiety disorder in China. Chin Med J (Engl). 2011 Oct;124(20):3260-3268.

30. Dhillon S. Duloxetine: a review of its use in the management of major depressive disorder in older adults. Drugs Aging. 2013, 30(1):59-79.

31. Harada E, Tokuoka H, Fujikoshi S, Funai J, Wohlreich MM, Ossipov MH, Iwata N.Is duloxetine's effect on painful physical symptoms in depression an indirect result of improvement of depressive symptoms? Pooled analyses of three randomized controlled trials. Pain. 2016 Mar;157(3):577-584.

32. Emslie GJ, Prakash A, Zhang Q, Pangallo BA, Bangs ME, March JS.A double-blind efficacy and safety study of duloxetine fixed doses in children and adolescents with major depressive disorder. $\mathrm{J} C$ ild Adolesc Psychopharmacol. 2014 May;24(4):170-179.

33. Papakostas GI. Antidepressants and their effect on cognition in major depressive disorder. J Clin Psychiatry. 2015 Aug;76(8):e1046.

34. Dueñas H, Brnabic AJ, Lee A.Treatment-emergent sexual dysfunction with SSRIs and duloxetine: effectiveness and functional outcomes over a 6-month observational period. Int J Psychiatry Clin Pract. 2011,15(4):242-254.

35. Hong J, Novick D, Montgomery W, Moneta MV, Dueñas H, Peng X, Haro JM.Health-related quality of life in patients with depression treated with duloxetine or a selective serotonin reuptake inhibitor in a naturalistic outpatient setting. Patient Prefer Adherence. 2015 Oct 16;9:1481-1490.

36. Bochsler L, Olver JS, Norman TR. Duloxetine in the acute and continuation treatment of major depressive disorder. Expert Rev Neurother. 2011,11(11):1525-1539.

37. Brunton S, Wang F, Edwards SB, Crucitti AS, Ossanna MJ, Walker DJ, Robinson MJ. Profile of adverse events with duloxetine treatment: a pooled analysis of placebo-controlled studies. Drug Saf. 2010; 33(5): 393-407. 